\title{
THE RIGHT VENTRICLE AND SMALL PULMONARY ARTERIES IN ANEURYSMAL DILATATION OF THE LEFT ATRIUM
}

\author{
BY
}

\author{
P. V. BEST AND DONALD HEATH
}

From the Departments of Pathology, Universities of Aberdeen and Birmingham

Received July 17, 1963

The original and subsequent early reports of aneurysmal dilatation of the left atrium (Owen and Fenton, 1901; Jones, 1901; Owen, 1902; Lutembacher, 1917, 1918; Emanuel, 1923; Shaw, 1924; Schott, 1924; East, 1926; Cowan, 1926) were collected together and analysed by Bramwell and Duguid (1928). They concluded that two main factors were concerned in the ætiology of this condition. A "passive factor" was gross fibrosis of the wall of the left atrium: this was usually, but not always, due to chronic rheumatic heart disease that had predominantly affected this chamber. An "active factor" was increased flow of blood into the inelastic fibrous left atrium commonly from a hypertrophied left ventricle through an incompetent mitral valve. They stated that "one cannot fail to be impressed by the fact that the condition is so constantly associated with great ventricular hypertrophy," and this applied in their collected series of cases not only to the left ventricular hypertrophy associated with mitral incompetence but also to right ventricular hypertrophy. Of the 20 cases in their series the state of the right ventricle at necropsy was specified in 13, and in 10 of these it was said to be hypertrophied. Wood (1954) also stated that "mitral incompetence is a more important cause of left atrial dilatation than mitral stenosis". In the face of these data and opinions we thought it would be of interest to see how many of our cases coming to necropsy, with extreme dilatation of the left atrium, had mitral incompetence, right ventricular hypertrophy, and pulmonary vascular disease.

\section{SubJECTS AND METHOD}

Necropsy material was available from nine patients with extreme dilatation of the left atrium who had died of chronic rheumatic heart disease. Five were men (Table).

At necropsy the thickness of the right ventricle and the size of the mitral valve orifice had been measured. Paraffin-embedded blocks of lung were available. Thin sections of lung were stained to demonstrate elastic tissue by the Lawson modification of the Weigert-Sheridan method and counterstained for collagen and muscle with van Gieson's reagents. Measurements were made of the external diameter of the media and average thickness of the media of pulmonary arteries up to $300 \mu$ in diameter, which had been sectioned as nearly as possible transversely. Only vessels that were virtually circular in transverse section were measured; this method of selection decreased the number of arteries included in each study but avoided error in the measurement of the vessel diameter. Approximately 15 to 40 small muscular pulmonary arteries were measured in each case. The external diameter was taken as the mean of two measurements, at right angles to each other, of the distance between diametrically opposite points on the external elastic lamina. The medial thickness was estimated as the mean of four measurements taken at points approximately equally spaced around the vessel wall. From these data the thickness of the media was expressed as a percentage of the external diameter of the artery. This technique was employed as we and other authors (Granston, 1958; 


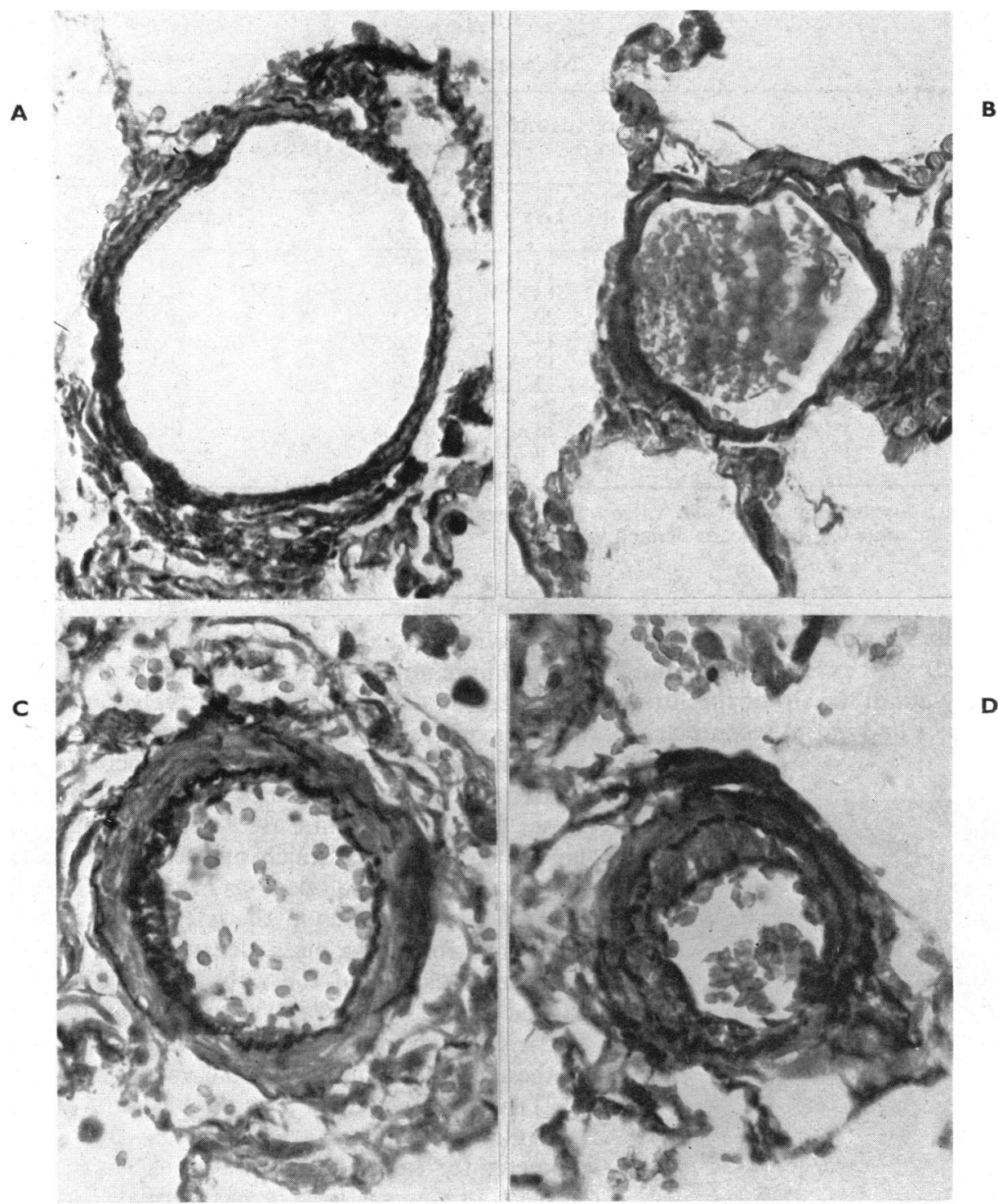

B 
TABLE

NeCropsy DATA

\begin{tabular}{|c|c|c|c|c|c|c|c|c|c|}
\hline \multirow{2}{*}{$\begin{array}{l}\text { Case } \\
\text { No: }\end{array}$} & \multirow{2}{*}{$\begin{array}{c}\text { Age } \\
\text { and sex }\end{array}$} & \multirow{2}{*}{$\begin{array}{c}\text { Weight } \\
\text { of heart } \\
\text { (g.) }\end{array}$} & \multicolumn{2}{|c|}{$\begin{array}{c}\text { Thickness of ventricles } \\
(\mathrm{mm} .)\end{array}$} & \multirow{2}{*}{$\begin{array}{c}\text { State of } \\
\text { mitral } \\
\text { valve }\end{array}$} & \multirow{2}{*}{$\begin{array}{c}\text { Other } \\
\text { valves } \\
\text { involved }\end{array}$} & \multirow{2}{*}{$\begin{array}{l}\text { Ante- } \\
\text { mortem } \\
\text { thrombus } \\
\text { in left } \\
\text { atrium }\end{array}$} & \multirow{2}{*}{$\underset{\text { thickness }}{\text { Medial }}$} & \multirow{2}{*}{$\begin{array}{c}\text { Grade } \\
\text { of } \\
\text { H.P.V.D.D. }\end{array}$} \\
\hline & & & Right & Left & & & & & \\
\hline $\begin{array}{l}1 \\
2 \\
3 \\
4 \\
5 \\
6 \\
7 \\
8 \\
9\end{array}$ & $\begin{array}{ll}57 & \mathrm{M} \\
54 & \mathrm{M} \\
43 & \mathrm{~F} \\
49 & \mathrm{~F} \\
41 & \mathrm{M} \\
44 & \mathrm{M} \\
52 & \mathrm{M} \\
52 & \mathrm{~F} \\
48 & \mathrm{~F}\end{array}$ & $\begin{array}{r}660 \\
560 \\
480 \\
320 \\
610 \\
530 \\
900 \\
420 \\
1300\end{array}$ & $\begin{array}{r}3 \\
4 \\
4 \\
4 \\
4 \\
5 \\
8 \\
10 \\
11\end{array}$ & $\begin{array}{r}20 \\
13 \\
20 \\
14 \\
15 \\
12 \\
20 \\
13 \\
9\end{array}$ & $\begin{array}{l}I \\
\text { SI } \\
\text { S } \\
\text { S } \\
\text { S } \\
\text { S } \\
\text { S } \\
\text { S } \\
\text { S }\end{array}$ & $\begin{array}{l}\bar{A} \\
\bar{A} \\
A \\
\text { AT } \\
\frac{A}{A T}\end{array}$ & $\begin{array}{r}0 \\
0 \\
0 \\
+ \\
0 \\
+ \\
+ \\
0 \\
++\end{array}$ & $\begin{array}{l}4 \cdot 8 \\
4 \cdot 4 \\
3 \cdot 2 \\
5 \cdot 7 \\
4 \cdot 0 \\
5 \cdot 3 \\
6 \cdot 8 \\
4 \cdot 4 \\
9 \cdot 9\end{array}$ & $\begin{array}{l}0 \\
0 \\
0 \\
0 \\
0 \\
0 \\
3 \\
3 \\
6\end{array}$ \\
\hline
\end{tabular}

I=incompetent; $S=$ stenotic; $A=$ aortic valve; $T=$ tricuspid valve; H.P.V.D. = hypertensive pulmonary vascular disease ${ }^{*}=$ mean value for the case, as defined in the text.

\section{RESULTS}

The results are shown in detail in the Table. With one exception (Case 4) the weight of the heart was increased. All except Cases 1 and 2 had tight pure mitral stenosis so that the mitral valve orifice would barely admit the tip of the little finger; there was calcification of the valve cusps in Cases 6 and 8. Case 1 had mitral incompetence, the valve orifice admitting three fingers with ease. Case 2

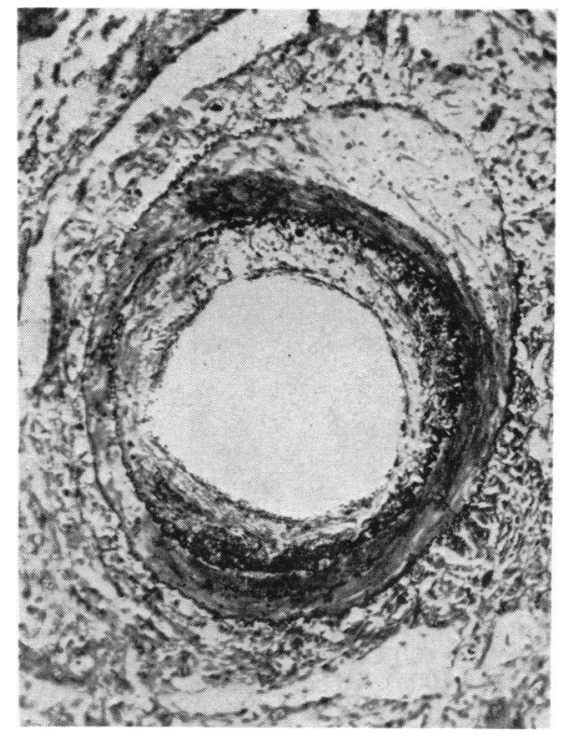

Fig. 2.-Case 9. Transverse section of a larger muscular pulmonary artery (approx. 380 $\mu$ ) showing fibrinoid necrosis. To the left the media has lost its characteristic tinctorial properties with van Gieson's stain. Above, the media is greatly swollen. (Elastic van Gieson $\times 115$.) had combined mitral stenosis and incompetence. The dilated left atrium contained ante-mortem thrombus in Cases 4, 6, 7, and 9: in Case 9 the thrombus was old and laminated and filled much of the cavity of the dilated atrium occluding the openings of three of the pulmonary veins. The thrombus in the left atrium in Case 7 was also large, forming a mass measuring $8 \times 6 \times 5 \mathrm{~cm}$. The average thickness of the right ventricle in these cases ranged from $3 \mathrm{~mm}$. (Case 1) to $11 \mathrm{~mm}$. (Case 9). The aortic valve was involved in six of the cases, and in two of these there was also tricuspid valve involvement.

The mean value of the thickness of the media of muscular pulmonary arteries below $300 \mu$ in external diameter for each of the Cases 1 to 9 is included in the Table. In Cases 1 to 6 it was normal (Fig. 1A and B). In Cases 7 and 9 it was unequivocally increased (Fig. $1 \mathrm{C}$ and D). In Case 9 the small pulmonary arteries showed healing necrotizing arteritis (Fig 2). In Case 8, although the medial thickness of pulmonary arteries less than $300 \mu$ in diameter was normal, that of larger arteries was in the range of 13 to 22 per cent of the external diameter. The small muscular pulmonary arteries showed intimal fibrosis in all nine cases. Expressing these results in general terms, Cases 1 to 6 showed no evidence of hypertensive pulmonary vascular disease. Cases 7 and 8 showed Grade III lesions and Case 9 had Grade VI lesions (Heath and Edwards, 1958). 


\section{DisCUSSION}

Bramwell and Duguid (1928) collected published reports and found mitral incompetence at necropsy in 6 of 14 cases of aneurysmal dilatation of the left atrium due to chronic rheumatic heart disease: in two others the mitral valve was thickened but not stenosed. This association convinced them that increased flow of blood ejected by a hypertrophied left ventricle into an atrium weakened by fibrosis was the essential factor in the atiology of the condition. However, in the present series only one (Case 1) had mitral incompetence and 7 others had pure stenosis that was so tight in the majority of instances as barely to allow the passage of the tip of the little finger through the mitral valve orifice. The patient with mitral incompetence had left ventricular hypertrophy but only two of the others (Cases 3 and 7) showed this, and in both of these there was associated aortic valve disease. Similarly in the patient described by Burkhardt (1930) there was pure stenosis of the mitral valve and the left ventricle was only $1.2 \mathrm{~cm}$. thick. In the case reported by Ashworth and Jones (1946) the "enormously dilated left atrium" was associated with severe mitral stenosis and a left ventricle only $1.0 \mathrm{~cm}$. thick. Hence neither mitral incompetence nor left ventricular hypertrophy appear to be necessary for the development of aneurysmal dilatation of the left atrium.

Bramwell and Duguid (1928) found right ventricular hypertrophy in 10 of the 13 cases in their collection in which necropsy had been performed and in which the state of the right ventricle was commented upon. From this one assumes that hypertensive pulmonary vascular disease would occur with aneurysmal dilatation of the left atrium. The present series of cases shows that this is not so since only 3 (Cases 7 to 9) had right ventricular hypertrophy and only 2 of these (Cases 7 and 9) showed increased medial thickness in the muscular pulmonary arteries. Indeed, since all but Case 1 of the present series had severe mitral stenosis one might justifiably come to the diametrically opposite conclusion that in some way extreme dilatation of the left atrium was associated with a failure to develop hypertensive pulmonary vascular disease. In fact in two of the three instances of giant left atrium with right ventricular hypertrophy (Cases 7 and 9) the cavity of the dilated chamber had been secondarily reduced in size by ante-mortem thrombus. In the patient showing the most severe right ventricular hypertrophy with healing necrotizing arteritis of the small pulmonary arteries (Case 9) the laminated thrombus was so extensive as to have considerably reduced the size of the left atrium and partially occluded pulmonary veins. In the case of Burkhardt (1930) the enlarged left atrium measured $25 \mathrm{~cm}$. laterally and $15 \mathrm{~cm}$. above the mitral valve and in its fixed (and hence contracted) state held $593 \mathrm{ml}$. of fluid, and yet the right ventricle was only $3 \mathrm{~mm}$. thick. In the case of Ashworth and Jones (1946) an enormously dilated left atrium had eroded the fifth to ninth thoracic vertebral bodies but again the right ventricle was only 3 to $4 \mathrm{~mm}$. thick. These data all suggest that aneurysmal dilatation of the left atrium is frequently associated with a failure of development of hypertensive pulmonary vascular disease in mitral stenosis. It is of interest to note that at the other extreme Wood (1954) found that cases of mitral stenosis with very high pulmonary vascular resistance exceeding 1000 dynes/sec./cm. ${ }^{-5}$ had but slight dilatation of the left atrium.

In this respect it is noted that many authors have been impressed by the unusually good prognosis of those patients with mitral valve disease who develop aneurysmal dilatation of the left atrium. Bramwell and Duguid (1928) stated that "a surprising feature in many of these cases is the comparative well-being of the patients for several years after extensive cardiac damage must have already been established." Parkinson (1936), describing this lesion, said "it possesses clinical features of great interest such as the moderate symptoms which may accompany a heart so hugely dilated." Daley and Franks (1949) found "the ability of these patients to carry out a full day's work was remarkable." Bramwell and Duguid (1928) thought that the capacity of the heart often to discharge its function so effectively was due to the fact that the brunt of the lesion was borne by "that relatively unimportant chamber, the auricle." It seems more likely that this benign clinical course was due to the failure of development of hypertensive pulmonary vascular disease as in the majority of the patients in the present series. Daley and Franks (1949) believed this, stating that the moderate symptomatology "was in keeping with the common lack of pulmonary hypertension," and they 
recognized that, if raised pulmonary arterial pressure supervened, the clinical state differed little from that found in the more usual types of mitral valvular disease with progressive dyspnœa. Their impression was purely clinical, but the histological findings in the lungs in the present series confirm their views.

We have no wish to substitute one generalization for another by maintaining that the opposite view to that held by earlier authors is always true. Rather we would point out that the classic associations of mitral incompetence and "great ventricular hypertrophy" are not present in every case of aneurysmal dilatation of the left atrium, and that when this chamber dilates excessively in association with tight mitral stenosis hypertensive pulmonary vascular disease tends not to develop.

\section{SUMMARY}

In 9 cases of aneurysmal dilatation of the left atrium the state of the mitral valve, the thickness of both ventricles, and the medial thickness of the muscular pulmonary arteries were recorded. In 7 there was tight pure mitral stenosis, in 1 there was combined stenosis and incompetence, and in 1 there was mitral incompetence. Only 3 showed right ventricular hypertrophy and hypertensive pulmonary vascular disease and in 2 of these the capacity of the left atrium had been secondarily reduced by laminated thrombus. These findings suggest that in some instances of tight mitral stenosis, extreme dilatation of the left atrium is in some way the cause, or the result of failure of development of hypertensive pulmonary vascular disease.

We wish to thank Professor W. Melville Arnott, Dr. O. Brenner, and Professor K. W. Donald for permission to report these cases. We are indebted to Dr. William Whitaker for his critical reading of the manuscript.

\section{REFERENCES}

Ashworth, H., and Jones, A. Morgan (1946). Aneurysmal dilatation of the left auricle with erosion of the spine. Brit. Heart J., 8, 207.

Bramwell, J. Crighton, and Duguid, J. B. (1928). Aneurysmal dilatation of the left auricle. Quart. J. Med., $21,187$. Burkhardt, E. A. (1930). Marked dilatation of the left auricle of the heart. Amer. J. Path., 6, 463.

Cowan, J. M. (1926). The failing heart. Edinb. med. J., n.s., 33, 550.

Daley, R., and Franks, R. (1949). Massive dilatation of the left auricle. Quart. J. Med., n.s., $18,81$.

East, C. F. T. (1926). Great dilatation of the left auricle. Lancet, 1, 1194.

Emanuel, J. G. (1923). Extreme dilatation of the left auricle. Lancet, 1, 591.

Granston, A. S. (1958). Morphologic alterations of the pulmonary arteries in congenital heart disease. Proc. Inst. Med. Chic., 22, 116.

Heath, D., and Best, P. V. (1958). The tunica media of the arteries of the lung in pulmonary hypertension. J. Path. Bact., 76, 165.

, and Edwards, J. E. (1958). The pathology of hypertensive pulmonary vascular disease. Circulation, 18, 533.

Jones, A. E. (1901). Calcification of the pericardium. Trans. path. Soc. Lond., 52, 181.

Lutembacher, R. (1917). Anévrisme de l'oreillette gauche; contribution à l'étude du rythme bigéminé. Arch. Mal. Ceeur, 10, 145.

- (1918). Deux nouveaux cas d'anévrisme de l'oreillette gauche. Arch. Mal. Caur, $11,434$.

Owen, I. (1902). Horizontal dilatation of the left auricle. Trans. clin. Soc. Lond., 35, 147. , and Fenton, W. J. (1901). A case of extreme dilatation of the left auricle of the heart. Trans. clin. Soc. Lond., 34, 183.

Parkinson, J. (1936). Enlargement of the heart. Lancet, 1, 1391.

Schott, A. (1924). Zur Kenntnis der hochgradigen Erweiterung des linken Vorhofes. Klin. Wschr., 3, 1067.

Shaw, H. Batty (1924). A case of horizontal dilatation of the left auricle. Lancet, $2,493$.

Wagenvoort, C. A. (1960). Vasoconstriction and medial hypertrophy in pulmonary hypertension. Circulation, 22, 535 .

Wood, P. (1954). An appreciation of mitral stenosis. Part II. Investigations and results. Brit. med. J., 1, 1113. 